\title{
Impact of cancers on the kidney function and structure; an ignored entity
}

\author{
Mohammad Davoodi' ${ }^{1}$, Sara Bahadoram², Mohammad Bahadoram ${ }^{3}$, Maedeh Barahman ${ }^{4}$, Zaher Khazaei $^{5}$, \\ Masoud Amiri ${ }^{6,7^{*}}$ \\ ${ }^{1}$ Department of Radiology, School of Medicine, Ahvaz Jundishapur University of Medical Sciences, Ahvaz, Iran \\ ${ }^{2}$ Department of Pediatrics, Imam Khomeini Hospital Complex, Tehran University of Medical Sciences, Tehran, Iran \\ ${ }^{3}$ Medical Student Research Committee and Social Determinant of Health Research Center, Ahvaz Jundishapur University of Medical \\ Sciences, Ahvaz, Iran \\ ${ }^{4}$ Department of Radiation Oncology, Firoozgar Hospital, Firoozgar Clinical Research Development Center (FCRDC), Iran University of \\ Medical Sciences (IUMS), Tehran, Iran \\ ${ }^{5}$ Epidemiology, Department of Health and Community Medicine, Faculty of Medicine, Dezful University of Medical Sciences, Dezful, Iran \\ ${ }^{6}$ Social Determinants of Health Research Center and Department of Epidemiology and Biostatistics, Shahrekord University of Medical \\ Sciences, Shahrekord, Iran \\ ${ }^{7}$ Department of Epidemiology, Erasmus Medical Center, Rotterdam, the Netherlands
}

\section{A R T I C L E I N F O}

\section{Article Type:}

Review

\section{Article History:}

Received: 11 January 2018

Accepted: 23 April 2018

Published online: 6 May 2018

\section{Keywords:}

End-stage renal disease, Renal cell carcinoma, Kidney transplantation, Cancer, Acute kidney injury, Lung cancer

\begin{abstract}
A B S T R A C T
Important declines have been observed in urological cancer-related mortality in recent decades, mainly due to improvements in treatments of prostate cancer, less exposure to tobacco smoking as well as occupational carcinogens of kidney and bladder. However, because of global population ageing, age-related urinary tract cancers are expected to increase in the near future despite improved primary prevention, early detection and more efficient treatment. In this article, renal cell carcinoma (RCC), kidney transplantation, cancer and acute kidney injury (AKI), lung cancer and chronic kidney disease (CKD), breast cancer, prostate cancer, cervix cancer and brain cancer and their associations with kidney function and structure have been discussed. In conclusion, kidney and cancers have interaction with each other. Kidney carcinoma can be metastasizing to other organs as well as other cancer to kidney. Therefore, it is recommended to consider the potential effect of kidney functions and interaction with other cancers in each malignancy.
\end{abstract}

Implication for health policy/practice/research/medical education:

According to global population ageing, age-related urinary tract cancers are expected to increase in the near future despite improved primary prevention, early detection and more efficient treatment.

Please cite this paper as: Davoodi M, Bahadoram S, Bahadoram M, Barahman M, Khazaei Z, Amiri M. Impact of cancers on the kidney function and structure; an ignored entity. J Renal Inj Prev. 2018;7(3):112-115. doi: 10.15171/jrip.2018.26.

\section{Introduction}

Important declines have been observed in urological cancer-related mortality in recent decades, mainly due to improvements in treatments of prostate cancer, less exposure to tobacco smoking as well as occupational carcinogens of kidney and bladder (1). However, because of global population ageing, age-related urinary tract cancers are expected to increase in the near future despite improved primary prevention, early detection and more efficient treatment (1). Active surveillance from renal failure and cancer patients could also be declined the mortality from these diseases (2). In addition, approximately $2 \%$ to $5 \%$ of all kidney cancers may originate from inheritance, with about 10 potential cancer susceptibility to increase the risk of renal cancer, with red flags of multiplicity of tumors, unusual or pathogenic pathology or early age of onset (3). On the other hand, the involvement of kidney with other tumors may present as isolated solitary lesions which is not an end-stage renal disease (ESRD), that is sometimes the first and only site 
of metastatic involvement in patients (4). Primary tumors that typically metastasize to the kidney are located in the lungs, breasts, esophagus and colon and melanoma. In the following paragraphs, renal cell carcinoma (RCC), kidney transplantation, cancer and acute kidney injury (AKI), lung cancer and chronic kidney disease (CKD), breast cancer, prostate cancer, cervix cancer and brain cancer and their associations with kidney function and structure have been discussed.

\section{Materials and Methods}

For this review, we used a variety of sources including PubMed/Medline, EBSCO, EMBASE, Web of Science, Google Scholar, Scopus and directory of open access journals (DOAJ). The search was conducted by using combinations of the following keywords and/or their equivalents; end-stage renal disease, renal cell carcinoma, kidney transplantation, cancer, acute kidney injury (AKI), lung cancer, chronic kidney disease, breast cancer, prostate cancer, cervix cancer, brain cancer, renal transplantation, renal replacement therapy and adenocarcinoma.

\section{Renal cell carcinoma and kidney function}

RCC, named also as hypernephroma or Grawitz's tumor and the most prevalent tumor affecting on adults' kidney, responsible for at least $80 \%-90 \%$ of primary malignancies of renal cancers in adults (5), is the eighth most common cancer among US adults (5) and $2 \%$ of all cancers (6). In fact, RCC is the seventh and ninth most common cancer worldwide among men and women, respectively (7). The median age for diagnosis of RCC is around 65 years (2). In addition, there are different associated genetic factors related to increasing incidence rates of RCC such as hereditary papillary renal cancer, von Hippel-Lindau disease and tuberous sclerosis (8). Therefore, more specialized follow-up is required, especially for patients with ESRD and von Hippel-Lindau disease (9). Moreover, RCC may have an unpredictable time course, having recurrence-free intervals even up to 30 years. Thus, prolonged of follow-up is needed (10). Furthermore, there are many risk factors of RCC (11) such as tobacco use (12) and exposure to some environmental factors like cadmium, asbestos, thorium dioxide and petroleum products; therefore, some professions are at higher risks such as leather tanners, shoe workers as well as asbestos workers (11). There are also other risk factors including obesity, hypertension and long-term administration of analgesics, especially among those containing phenacetin (12).

The most common diagnosis among patients who were referred with neurologic complications of systemic malignancy could be brain metastases (12). In addition, brain metastasis was prevalent in patients with lung carcinoma and renal carcinoma but not in breast carcinoma (12). Moreover, It is reported that Sunitinib could be effective and safe to considerable inhibition of brain metastasis with no important adverse effect in patients with brain metastases from RCC (13). It should be mentioned that brain metastases are not rare in RCC, even in the patients with a history of nephrectomy even 10 years before presentation (14).

\section{Renal transplantation and kidney cancers}

It is believed that kidney transplantation is now a gold standard treatment for ESRD (15). Kidney transplantation recipients have shown higher incidence rates of malignancies in recent decades because of increasing survival rates of these patients $(16,17)$.

Malignancy is one of the leading causes of death in the recipients of kidney transplantation. The prevalence of cancer has increased by twofold to threefold among kidney transplant recipients compared with the general public. This risk growth is not proportionate among all types of cancer though, while the prevalence of some kinds of cancers will not increase (breasts, prostate, ovary, brain and cervix) some other types increase (lungs, colon, liver, lymphoma, melanoma, and non-melanoma skin cancers). Carcinoma related mortality rate is also higher among the recipients of kidney transplantation in comparison with the general public. Patient, transplantation, and drugs are effective factors in the increased risk of cancer following kidney transplantation. Immunosuppressive drugs are the most important risk factor as they decrease immunologic control of viral-oncologic infections and immunesurveillance. Although it is an assumed fact that increased immunosuppressive dosage is associated with an increased risk of cancers secondary to kidney transplantation, the disruptive effects of immunosuppressive agents are not fully known yet (18).

\section{Acute kidney injury in cancers}

Cancer patients may have the complication of AKI, through renal infiltration by malignant cells or metabolic disturbances or drug-induced toxicity or sepsis, which is important for increasing morbidity and mortality rates as well as potential effect on the cancer treatment through decreasing chemotherapy dosage or contradiction with the cancer treatment (19). In fact, approximately 10 to 50 percent of cancer patients may experience AKI whom about 10 to more than $30 \%$ of them might need renal replacement therapy (RRT) during their hospitalization in intensive care unit (ICU) $(20,21)$. In addition, melanoma, breast, lung, esophagus and colon cancers are the most common malignancies that could metastasize to kidney, leading to large, solitary mass lesions (22).

\section{Lung cancer and kidney}

Non-small cell lung cancer can be metastasizing to kidney (23). In addition, it has been confirmed that lung cancer and CKD may have a similar course and survival in comparison with the patients with lung cancer without $\mathrm{CKD}$, which it means that these two diseases could receive the same benefit from treatment (24). However, it has also approved that CKD could not be an independent 
risk factor for survival in patients with lung cancer (25). Moreover, progressive renal failure was observed in patients with lung adenocarcinoma (26).

In spite of great advances in the care non-small cell lung cancer (NSCLC) tumor, 5-year survival rate of NSCLC is still less than 15\%. More than one-third of NSCLC patients are diagnosed with distant metastasis because of failure of diagnosis in preliminary stages. Main factors endangering a patient's life originate from local signs of tumor and complications from distant metastasis of NSCLC. The most common site of hematogenous metastasis is brain, followed by bone, liver, adrenal gland and the lung. Renal parenchymal metastasis is fairly uncommon. Kidney metastases usually do not have clinical symptoms and most patients do not have hematuria or azotemia (27).

Based on the findings, metastatic kidney tumors are most often found in the cortical area near the glomerular vasculature and rarely spread to the urothelial tissue, thereby, the microscopic hematuria incidence is between $12 \%-31 \%$.

Since kidney blood flow comprises $20 \%$ of cardiac output, the kidneys are likely to be susceptible to blood metastasis. Although kidney metastasis from NSCLC is routinely observed in autopsy, clinical diagnosis of isolated metastasis to the kidneys is relatively rare. NSCLC renal localization is extremely uncommon. Most often, kidney metastasis is either part of a diffused disease or bilateral renal metastasis. Therefore, isolated kidney metastasis from NSCLC is particularly rare (28).

\section{Breast cancer and kidney}

Breast cancer metastasis is common in brain, lung, bones and liver bur rarely kidney (29). However, it is possible that metastasis of breast cancer leads to a solitary renal mass by extending into the renal vein, resulting in a primary renal tumor (29). Therefore, histopathological examinations of kidney are suggested in breast cancer patients, due to the fact that in these patients appropriate systematic treatment is better than nephrectomy (29). In addition, although metastasis to breast is rare, however, there is some evidence that renal cell cancer was metastasizing to breast mass (30).

\section{Prostate cancer and kidney}

Prostate cancer is the second most common cancer in men, as well as, the second most common cause of death from cancer in men. Prostate carcinoma comprises 15\% of all men's cancers in developed countries and $4 \%$ of men's cancers in developing countries. Typically, prostate cancer metastasizes to the bone, lungs, and liver and locally invades the seminal vesicles, bladder, rectum, and regional lymph nodes (31).

However, renal mass lesion should be considered in primary tumor metastasis, especially among the left size localized patients (32). Theoretically, malignancy can spread metastasis to any organ. However, prostate cancer is often related to pulmonary, hepatic or skeletal and rarely kidney (33). Moreover, it should also be considered the possibility of prostate metastases to kidney in renal mass patients with a history of prostate carcinoma (33).

Kidney is a rare metastatic site in prostate cancer. Since the kidney is a highly vascular organ, metastasis infiltration is likely due to vascular propagation.

\section{Cervical cancer and kidney}

Approximately 500000 cases of cervical cancer are detected each year worldwide, accounting for almost $5 \%$ of all cases of diagnosed cancers in the world. A vast majority of these cases (over 80\%) happens in the developing countries. Blood release from tumor cells is a hallmark of end-stage cervical cancer. The most common sites of such metastasis are the lungs, bones, aorta, and celiac and supraclavicular lymph nodes, whereas, kidney metastasis is rare (34).

A very common complication of advanced cervical cancer is obstructive nephropathy which one of the best techniques for resolving the obstruction could be ultrasonography-guided percutaneous nephrostomy (PCN) (35). In fact, PCN can recover renal function of more than $60 \%$ of cervical cancer patients, resulting in preventing renal replacement therapy in these patients (36). In addition, cervical cancer patients may develop hydronephrosis, as a cancer-related or cancer treatmentrelated complication, which is associated with higher morbidity and worse survival (35).

\section{Conclusion}

In conclusion, kidney and cancers have interaction on each other. Kidney carcinoma can be metastasizing to other organs as well as other cancer to kidney. Therefore, it is recommended to consider the potential effect of kidney functions and interaction with other cancers in each malignancy.

\section{Author's contribution}

$\mathrm{MD}, \mathrm{SB}, \mathrm{MB}, \mathrm{ZK}$ and $\mathrm{MB}$ searched the literature and gathered the data. MA prepared the primary draft. MB completed the paper. MA finalized the manuscript. All authors read and signed the final manuscript.

\section{Conflicts of interest}

The authors declared no competing interests.

\section{Ethical considerations}

Ethical issues (including plagiarism, data fabrication, double publication) have been completely observed by the authors.

\section{Funding/Support}

None.

\section{References}

1. Chlosta PL, Golabek T, Nyirady P. New Insights into Diagnosis and Treatment of Renal Cell Carcinoma, Bladder Cancer, and Prostate Cancer. Biomed Res Int 2017;2017:6467072. 
2. Yates DR, Roupret M. Small renal mass and low-risk prostate cancer: any more for active surveillance? Eur Urol 2011;60:45-7.

3. Cho E, Adami HO, Lindblad P. Epidemiology of renal cell cancer. Hematol Oncol Clin North Am 2011;25:651-65.

4. Adamy A, Von Bodman C, Ghoneim T, Favaretto RL, Bernstein M, Russo P. Solitary, isolated metastatic disease to the kidney: Memorial Sloan-Kettering Cancer Center experience. BJU Int. 2011;108:338-42.

5. Ng CS, Wood CG, Silverman PM, Tannir NM, Tamboli P, Sandler CM. Renal cell carcinoma: diagnosis, staging, and surveillance. AJR Am J Roentgenol 2008;191:1220-32.

6. Rajer M. Kidney cancer. Radiol Oncol. 2007;41:64-71.

7. Jemal A, Siegel R, Ward E, Murray T, Xu J, Thun MJ. Cancer statistics, 2007. CA Cancer J Clin. 2007;57:43-66.

8. Bjornsson J, Short MP, Kwiatkowski DJ, Henske EP. Tuberous sclerosis-associated renal cell carcinoma. Clinical, pathological, and genetic features. Am J Pathol 1996;149:1201-8.

9. Russo P. Renal cell carcinoma: presentation, staging, and surgical treatment. Semin Oncol. 2000;27:160-76.

10. Bos SD, Mensink HJ. Can duplex Doppler ultrasound replace computerized tomography in staging patients with renal cell carcinoma? Scand J Urol Nephrol 1998;32:87-91.

11. Michalski JM. Urinary tract tumors. In: Perez CA, Brady LW, Halperin EC, Schmidt- Ulrich RK, editors. Principles and practice of Radiation oncology. 4th ed. Philadelphia: Lippincott Williams \& Wilkins; 2004. p. 1649-63.

12. Schouten LJ, Rutten J, Huveneers HA, Twijnstra A. Incidence of brain metastases in a cohort of patients with carcinoma of the breast, colon, kidney, and lung and melanoma. Cancer 2002;94:2698-705

13. Koutras AK, Krikelis D, Alexandrou N, Starakis I, Kalofonos HP. Brain metastasis in renal cell cancer responding to sunitinib. Anticancer Res. 2007;27:4255-7.

14. Alshamsi H, Al Muhrij AR, Taha M, Al Mousa R. Brain Metastasis from Chromophobe Renal Cell Carcinoma. Int J Cancer Res Mol Mech. 2017;3(2).

15. Dholakia S, Johns R, Muirhead L, Papalois V, Crane J. Renal donors with prostate cancer, no longer a reason to decline. Transplant Rev (Orlando). 2016;30:48-50.

16. Campistol JM. Minimizing the risk of posttransplant malignancy. Transplantation. 2009;87:S19-22.

17. Webster AC, Wong G, Craig JC, Chapman JR. Managing cancer risk and decision making after kidney transplantation. Am J Transplant 2008;8:2185-91.

18. Sprangers B, Nair V, Launay-Vacher V, Riella LV, Jhaveri KD. Risk factors associated with post-kidney transplant malignancies: an article from the Cancer-Kidney International Network. Clin Kidney J. 2017; 27:1-15.

19. Darmon M, Ciroldi M, Thiery G, Schlemmer B, Azoulay E. Clinical review: specific aspects of acute renal failure in cancer patients. Crit Care 2006;10:211.

20. Benoit DD, Hoste EA, Depuydt PO, Offner FC, Lameire $\mathrm{NH}$, Vandewoude $\mathrm{KH}$, et al. Outcome in critically ill medical patients treated with renal replacement therapy for acute renal failure: comparison between patients with and those without haematological malignancies. Nephrol Dial Transplant 2005;20:552-8.

21. Azoulay E, Moreau D, Alberti C, Leleu G, Adrie C, Barboteu $\mathrm{M}$, et al. Predictors of short-term mortality in critically ill patients with solid malignancies. Intensive Care Med 2000;26:1817-23.

22. Denti F, Wisard M, Guillou L, Francke ML, Leisinger HJ. Renal metastasis from prostatic adenocarcinoma: a potential diagnostic pitfall. Urol Int 1999;62:171-3.

23. Barry-Brooks M, Yoo DC, Chaump M, Noto RB. Non-small cell lung cancer with unsuspected distant metastasis to the kidney seen on PET/CT. Med Health R I 2012;95:144-6.

24. Patel P, Henry LL, Ganti AK, Potti A. Clinical course of lung cancer in patients with chronic kidney disease. Lung Cancer. 2004;43:297-300.

25. Lu MS, Chen MF, Lin CC, Tseng YH, Huang YK, Liu HP, et al. Is chronic kidney disease an adverse factor in lung cancer clinical outcome? A propensity score matching study. Thorac Cancer. 2017;8:106-113.

26. Agrawal V, Ye J, McCann J, Hehn B, Freeman J, Allen $\mathrm{S}$, et al. Progressive renal failure in a patient with lung adenocarcinoma. NDT Plus. 2010;3:461-4.

27. Cai J, Liang G, Cai Z, Yang T, Li S, Yang J. Isolated renal metastasis from squamous cell lung cancer. Multidiscip Respir Med. 2013;8:2. doi: 10.1186/2049-6958-8-2.

28. Tomita M, Ayabe T, Chosa E, Nakamura K. Isolated Renal Metastasis from Non-Small-Cell Lung Cancer: Report of 2 Cases. Case Rep Surg. 2015;2015:357481. doi: $10.1155 / 2015 / 357481$.

29. Nasu H, Miura K, Baba M, Nagata M, Yoshida M, Ogura H, et al. Breast cancer metastatic to the kidney with renal vein involvement. Jpn J Radiol. 2015;33:107-11.

30. Pathe N, Raymond J, Cintra AU. Metastatic renal cell cancer presenting as a breast mass. Clin Adv Hematol Oncol 2012;10(2):124-6.

31. Khan F, Mahmalji W, Sriprasad S, Madaan S. Prostate cancer with metastases to the kidney: a rare manifestation of a common disease. BMJ Case Rep. 2013;2013:bcr2012008388. doi: $10.1136 /$ bcr-2012-008388.

32. Kurtul N, Resim S, Koçarslan S. Giant renal metastasis from prostate cancer mimicking renal cell carcinoma. Turk J Urol 2017:39225.

33. Khan F, Mahmalji W, Sriprasad S, Madaan S. Prostate cancer with metastases to the kidney: a rare manifestation of a common disease. BMJ Case Rep. 2013;2013.

34. Fan G, Xie YU, Pei X, Lei J, Ye M, Zeng G, et al. Renal metastasis from cervical carcinoma presenting as a renal cyst: A case report. Oncol Lett. 2015;10:2761-2764.

35. Patel K, Foster NR, Kumar A, Grudem M, Longenbach S, Bakkum-Gamez J, et al. Hydronephrosis in patients with cervical cancer: an assessment of morbidity and survival. Support Care Cancer. 2015;23:1303-9.

36. Souza AC, Souza AN, Kirsztajn R, Kirsztajn GM. Cervical cancer: Renal complications and survival after percutaneous nephrostomy. Rev Assoc Med Bras (1992). 2016;62:255-61.

Copyright (C) 2018 The Author(s); Published by Nickan Research Institute. This is an open-access article distributed under the terms of the Creative Commons Attribution License (http://creativecommons.org/licenses/by/4.0), which permits unrestricted use, distribution, and reproduction in any medium, provided the original work is properly cited. 